\title{
Ultrasound Markers of Aneuploidy in the First Trimester
}

\author{
'Zorán Belics, ${ }^{2}$ Zoltán Papp
}

\begin{abstract}
Prenatal screening of fetal aneuploidy is a continuously and rapidly evolving area of research; there have been tremendous advancements over the past decades in prenatal screening for aneuploidy, especially during the first trimester. As there is extensive evidence that effective screening for major chromosomal abnormalities can be provided in the first trimester of pregnancy, recently we have changed our practice; the prenatal screening of fetal chromosomal aberrations has been moved and pointed to the first trimester. Besides the nuchal translucency, which is one of the most known ultrasonographic markers, there are other markers, which can be examined during the first trimester of pregnancy. To maximize the quality of sonography, increase the screening sensitivity, and decrease the range of false-positive rate, all of the first-trimester ultrasound markers have well-established criteria for the measurement. With the use of high standards of scanning, the early recognition of sonographic markers of chromosomal aberrations can be helpful in forward prenatal diagnosis. On the contrary, the early diagnosis makes the termination of the pregnancy possible with fewer complications, and there is time for planning of further follow-up and interventions.
\end{abstract}

Keywords: Aneuploidy, First trimester, Marker, Screening, Ultrasound.

How to cite this article: Belics Z, Papp Z. Ultrasound Markers of Aneuploidy in the First Trimester. Donald School J Ultrasound Obstet Gynecol 2017;11(1):20-28.

Source of support: Nil

Conflict of interest: None

\section{INTRODUCTION}

With the evolution of ultrasound technology, a large gain in efficiency of detecting aneuploid pregnancies has occurred. The recent trend is to recognize and establish useful sonographic markers as soon as possible, especially at the first trimester of the pregnancy. Over the last decades, the advancements in medicine and technique have improved the methods of detection of chromosomal aberrations. A significant number of fetal structural anomalies develop by the end of the first trimester ${ }^{1}$;

\footnotetext{
${ }^{1}$ Associate Professor, ${ }^{2}$ Honorary Professor

${ }^{1}$ Department of Obstetrics and Gynecology, Ferenc Jahn Teaching Hospital, Budapest, Hungary

${ }^{2}$ Maternity Private Hospital for Obstetrics and Gynecology Semmelweis University, Budapest, Hungary

Corresponding Author: Zoltán Papp, Honorary Professor Maternity Private Hospital for Obstetrics and Gynecology Semmelweis University Budapest, Hungary, e-mail: papp. zoltan@maternity.hu
}

hence, besides the well-known second-trimester markers, there are real opportunities to recognize chromosomal abnormalities at an early gestational age.

During the first trimester, the ultrasound examination can be performed with the transvaginal or transabdominal technique (the recommended procedure is transabdominal sonogram). The most common chromosomal aneuploidy, such as trisomies 21,18, and 13, might have a characteristic appearance at the first trimester; however, the establishment of the early screening methods can give a real opportunity to decrease the prevalence of neonates born with chromosomal aberrations as soon as possible. The early recognition of sonographic markers of chromosomal aberrations can be helpful in forward prenatal diagnosis. On the contrary, the early diagnosis makes the termination of the pregnancy possible with fewer complications, and there is time for planning of further follow-up and interventions. Prenatal cytogenetic analysis or noninvasive testing should be offered to women with fetal ultrasound markers of aneuploidy diagnosed in the first trimester.

\section{NUCHAL TRANSLUCENCY}

In 1985, Benacerraf et $\mathrm{al}^{2}$ presented the ultrasound sign of enlarged nuchal fold thickness in second-trimester fetuses. In 1992, Nicolaides et al $^{3}$ described enlarged nuchal translucency (NT) in first-trimester fetuses with trisomy $21 .^{3}$ Nuchal translucency refers to the normal subcutaneous fluid-filled area between the back of the embryonal/fetal neck and the overlying skin (Fig. 1).

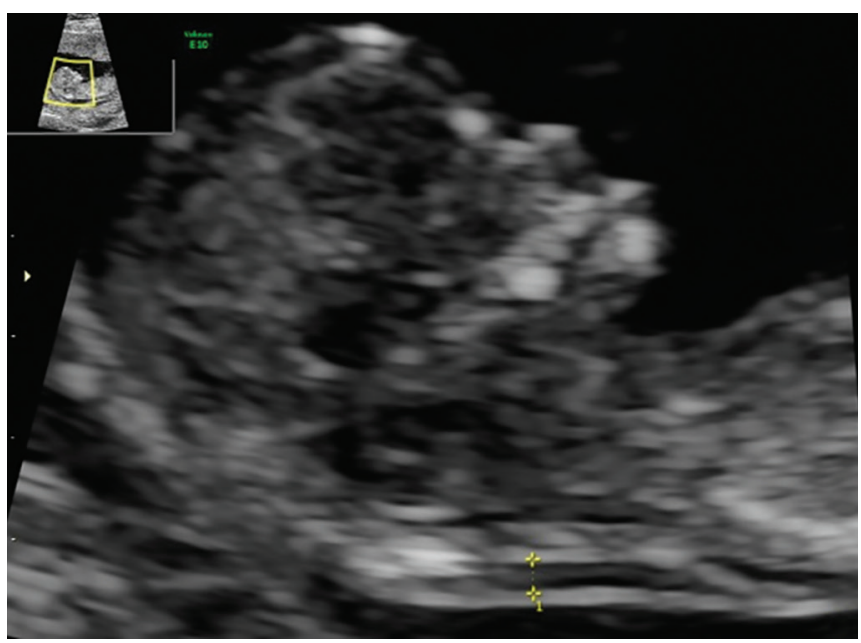

Fig. 1: The NT thickness in a 12-week fetus 




Figs 2A and B: (A) The procedure of the NT measurement; and (B) with the selected area zoomed into the calipers will be placed "on to on"

As a measurement mistake can have a major consequence, it is very important to establish the criteria for NT measurement. The Fetal Medicine Foundation (FMF) has introduced a process of training and certification to help establish high standards of scanning on an international basis. The FMF proposed sonographic criteria (Box 1) to maximize the quality of NT sonography, which were used successfully. ${ }^{4}$

Box 1: Sonographic criteria to maximize quality of nuchal

Fetal NT can be measured successfully by transabdominal ultrasound examination in about $95 \%$ of cases (in the others, it is necessary to perform transvaginal sonography - the results from transabdominal and transvaginal scanning are similar). ${ }^{4}$ For the sonographic examination of NT, the section obtained is a midsagittal section of the embryo/fetus [this is the section where the measure of the crown-rump length (CRL) is obtained].

Box 1: The NT measurement (FMF criteria)

- The gestation should be 11 to $13+6$ weeks and the fetal $\mathrm{CRL}$ should be 45 to $84 \mathrm{~mm}$.

- A midsagittal section of the fetus should be obtained and the NT should be measured with the fetus in the neutral position.

- Only the fetal head and upper thorax should be included in the image. The magnification should be as large as possible and always such that each slight movement of the calipers produces only a $0.1 \mathrm{~mm}$ change in the measurement.

- The maximum thickness of the subcutaneous translucency between the skin and the soft tissue overlying the cervical spine should be measured. Care must be taken to distinguish between fetal skin and amnion.

- The calipers should be placed on the lines that define the NT thickness - the crossbar of the caliper should be such that it is hardly visible as it merges with the white line of the border and not in the nuchal fluid.

- During the scan, more than one measurement must be taken and the maximum one should be recorded.

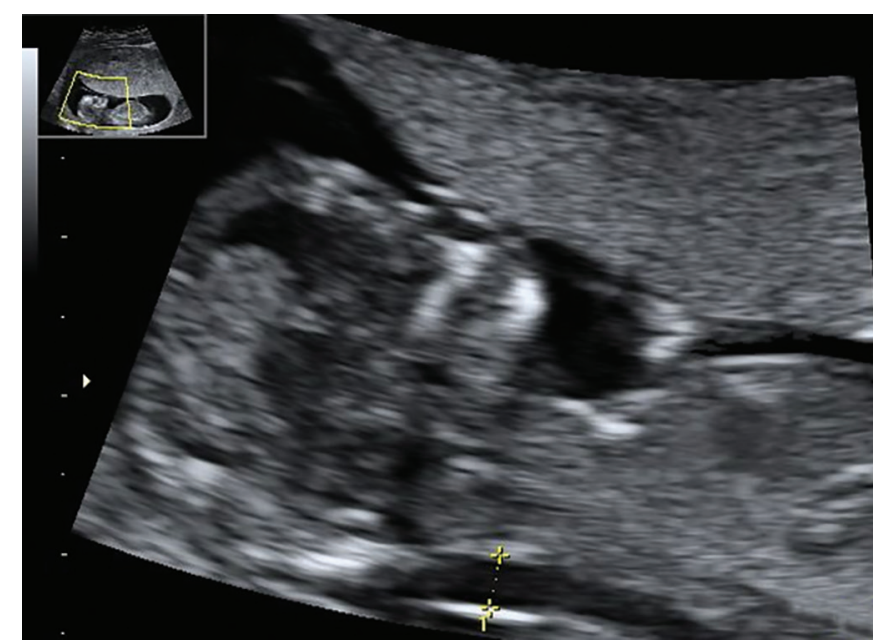

Fig. 3: Enlarged NT in a 12-week fetus

Only the fetal head and upper thorax should be included in the image for measurement of NT. The optimal gestational age for measurement of fetal NT is 11 weeks to 13 weeks and 6 days. The minimum fetal CRL should be $45 \mathrm{~mm}$ and the maximum $84 \mathrm{~mm}$. The procedure of the measurement should be performed exclusively at the level of maximum thickness of the subcutaneous translucency between the skin and soft tissues overlying the cervical spine (Fig. 2A). The calipers will be placed "on to on," perpendicular to the long axis of the fetal body (Fig. 2B). For adequate measurement, it is practical to zoom into the selected area.

Sometimes, a false-positive result in the measurement can happen if the amnion is not truly separated from the fetal skin (the movement of the fetus can account for these situations).

Furthermore, the umbilical cord or sometimes the presence of amnion band can also distract the measurement. For these reasons, application of the technique and training of the sonographers are very important.

The NT is usually considered abnormal if it is greater than $3 \mathrm{~mm}$, but it is known that NT thicknesses extend with the gestational age. According to the recent most proposed protocol, if the NT is $3 \mathrm{~mm}$ or larger, then genetic counseling is advisable.

The mechanism of fluid accumulation in the fetal neck, which produces the enlarged NT, is still unknown. ${ }^{5-8}$ However, it is possible that the physiopathological process leading to NT may be related to cardiac malformations, early hemodynamic disorders of the affected fetuses, or abnormalities of the extracellular matrix of the skin in fetuses with trisomy 21. ${ }^{9-11}$

In first-trimester scans (11-14 weeks), approximately 75 to $80 \%$ of fetuses with trisomy 21 present an enlarged NT (Fig. 3); however, 5 to $10 \%$ of healthy fetuses also show the same sign. ${ }^{12-14}$ Malone and D'Alton ${ }^{4}$ evaluated 30 studies on the subject. These studies describe 316,311 


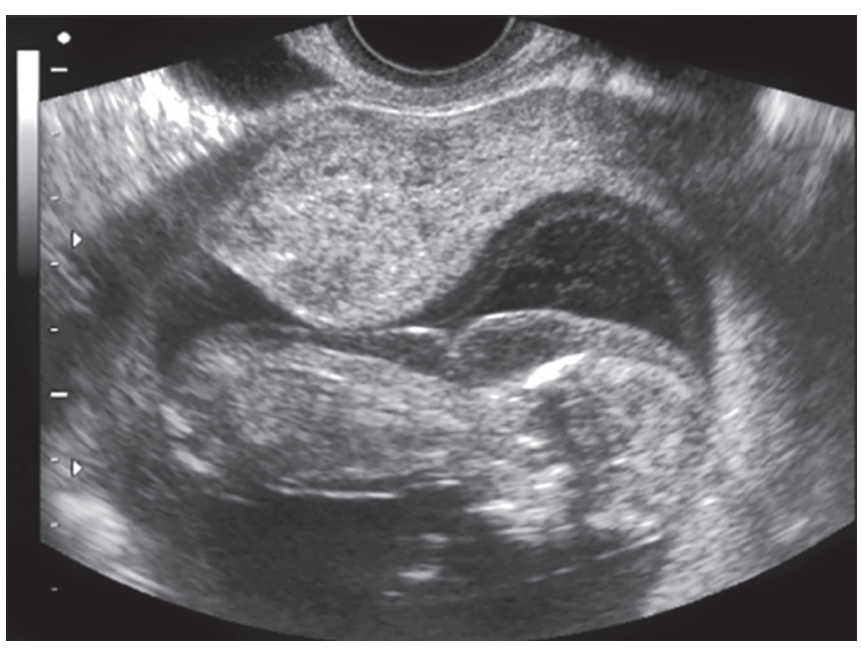

Fig. 4: Nonsepta cystic hygroma (sagittal plane)

patients who were screened with NT sonography during the first trimester of pregnancy. The overall sensitivity for trisomy 21 was $77 \%$, with a false-positive rate of $6 \%$ (sensitivities varying from 29 to $100 \%$, false-positive rates varying from 0.3 to $11.6 \%$ ). The study established that abnormal NT is 13 times more likely when trisomy 21 is present compared with the healthy fetuses.

In conjunction with maternal age, measurement of NT thickness between 11 and 14 weeks demonstrated a detection rate of $77 \% .{ }^{12,13}$ A combination of NT thickness measurement, maternal age indicator, and first-trimester serum markers should increase detection rates while avoiding false-positive findings. In this combination, the rate of detection is increased from 90 to $92 \%$ with a $3 \%$ false-positive rate. ${ }^{14-16}$ Furthermore, the combination of NT test with the maternal age of more than 35 years and ultrasound screening markers in the second trimester (which is practiced in most centers) has shown increase in accuracy of the screening test. Technique in NT imaging is essential for accurate risk assessment (undermeasurement by even $0.5 \mathrm{~mm}$ can reduce the test sensitivity by $18 \%$ ). ${ }^{17}$ The NT can be also enlarged in other chromosomal aberrations, such as trisomies 18 and 13, Turner's syndrome (monosomy X), Klinefelter's syndrome, and triploidy. ${ }^{12-18}$ Currently, the relatively small experience with three-dimensional (3D) technique of this subject does not show any advancement with the NT measurement.

\section{CYSTIC HYGROMA}

Fetal nuchal cystic hygroma (NCH) can be determined as an area of sonolucency in the soft tissue of the occipital region (Figs 4 and 5). The NCH consists of two symmetrical cavities completely separated by a nuchal ligament, with or without internal trabeculae (septated and nonseptated $\mathrm{NCH}$ ).

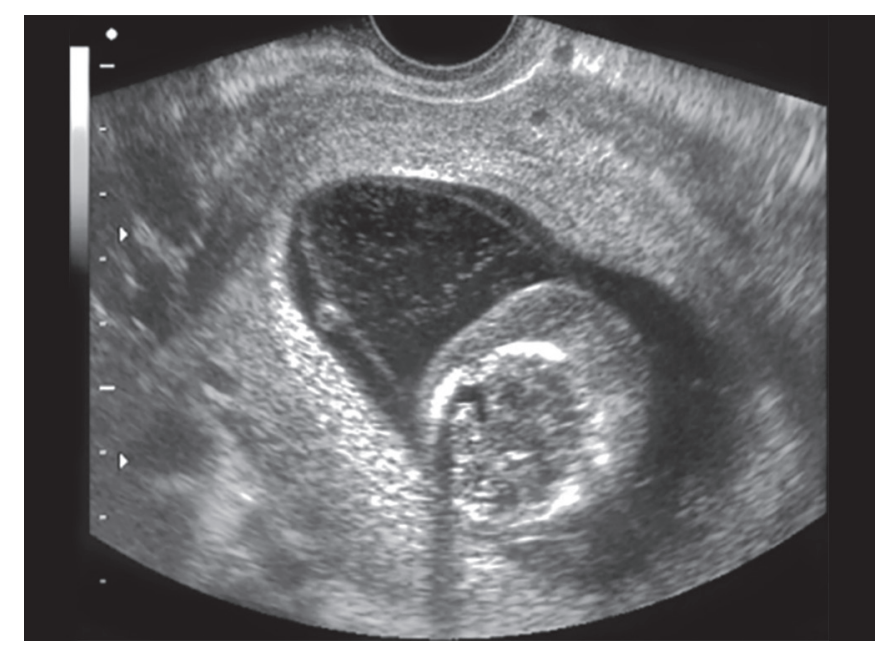

Fig. 5: Nonsepta cystic hygroma (transverse section)

The etiopathogenesis of the cystic hygroma is different from NT. The NCH is the congenital malformation of the lymphatic system (lymphatic stasis).

The association with chromosomal abnormalities, such as Turner's syndrome (the most common), trisomies 21, 18, and 13, and Klinefelter's syndrome, has been reported. ${ }^{19-24}$ The volume of hygroma and the presence of septa are associated with higher incidence of chromosomal aberrations. ${ }^{25}$

\section{FETAL GROWTH DISORDERS}

The biometry of embryo/fetus in the first trimester consists of the measurement of CRL (Fig. 6). During this time, biological variation in the fetal size is minimal. Fetal growth disorders in the first trimester could be associated with chromosomal aberrations; CRL, compared with what is expected, is substantially less. The CRL, i.e., smaller or more than $7 \mathrm{~mm}$ expected indicates a three times higher risk for chromosomal aberration. ${ }^{26}$ Trisomy 18 is associated with severe early-onset growth restriction, which is more severe than in trisomies 21 and 13. ${ }^{27,28}$

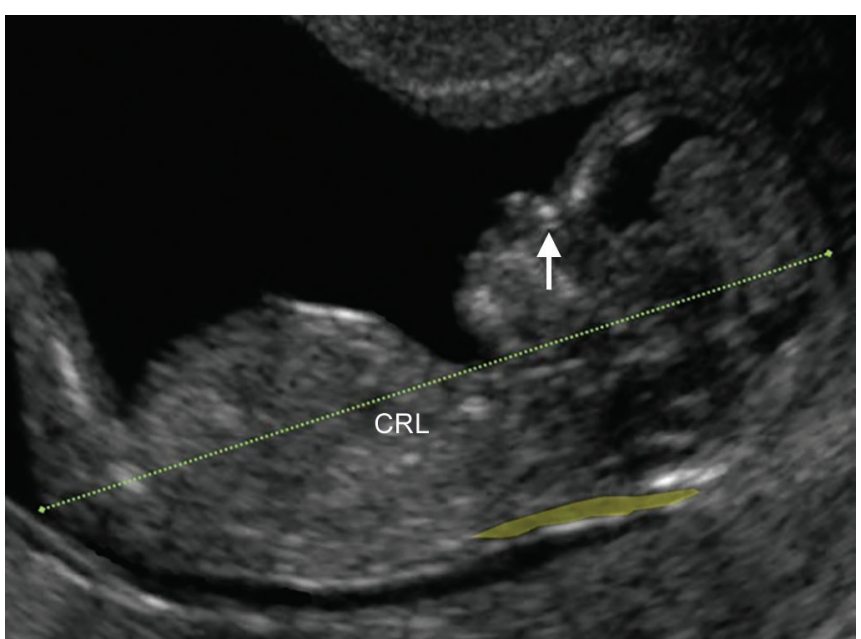

Fig. 6: Measurement of $C R L$ at first trimester 


\section{NASAL BONE}

The absence of the nasal bone can be a useful ultrasound marker for identifying fetuses with trisomy 21 in the first trimester of pregnancy. Among other chromosomal abnormalities, such as trisomies 9 and 18 and Turner's syndrome, different defects of the bone and connective tissue have been described, and the absence of nasal bone has been recognized. ${ }^{29}$ Between the 11th and 14th weeks of gestation, the fetal nasal bone can be visualized by ultrasonography in $99.5 \%$ of chromosomally normal fetuses. ${ }^{30}$ This finding is compatible with the results of histological and radiological studies of aborted fetuses, which showed that the intramembranous ossification process of the nasal bone first appears at a CRL of $42 \mathrm{~mm}$ and increases linearly with gestation. ${ }^{31}$ There is a significant difference in the rate of visualization of the fetal nasal bones in the first trimester in mothers of different ethnic origins. ${ }^{32}$

For visualization of the fetal nose (Box 2), the obtained section is a midsagittal view of fetal profile (Fig. 7), with an angle of incidence between the beam of the ultrasound transducer and the line traced from front to the chin of the fetus at about $45^{\circ}$ or $135^{\circ}$. The importance of

Box 2: Examination of the nasal bone (FMF criteria)

- The gestation should be 11 to $13+6$ weeks and the fetal CRL should be 45 to $84 \mathrm{~mm}$.

- The image should be magnified so that the head and the upper thorax only are included in the screen.

- A midsagittal view of the fetal profile should be obtained with the ultrasound transducer held in parallel to the direction of the nose.

- In the image of the nose, there should be three distinct lines. The top line represents the skin and the bottom one, which is thicker and more echogenic than the overlying skin, represents the nasal bone. A third line, almost in continuity with the skin, but at a higher level, represents the tip of the nose.



Fig. 7: Visualization of fetal nose in the midsagittal view of the fetal profile the angle of insonation cannot be underestimated; nasal bone may artificially appear to be absent if the angle is inadequate. ${ }^{33}$ In the midsagittal position, two echogenic lines can be seen, superficial line representing the skin of the nose, and the inner one representing the ossificated nasal bone (Fig. 8). ${ }^{34}$ The echoes from the skin of the nose can be misinterpreted as the nasal bone. ${ }^{30}$ To avoid this mistake, the ultrasound transducer must be gently tilted from side-to-side to ensure that the nasal bone was seen separately from the nasal skin. ${ }^{30}$

A full view of the fetal profile had a success rate of 94 to $99 \%$, meaning it was not always possible for sonographers to confirm the absence or presence of the nasal bone. $^{35}$

The process of ossification is extremely complex and numerous genetic syndromes and chromosomal anomalies can be implicated in the origin of alterations and defects in the development of the cranial skeleton. ${ }^{36-39}$ Among other things, the curiosity of the growing of fetal bone is dependent on the surrounding functional matrix. ${ }^{30}$ Immunohistochemical studies of fetuses with trisomy 21 have shown alterations in the composition of extracellular matrix, which might be attributed to gene dosage effects. ${ }^{10,11,40}$ This can be supported by the biochemical and molecular-genetic changes in trisomy 21 , namely trisomy 21 is associated with a substantial increase of hyaluronic acid. ${ }^{40}$ This increase could be a consequence of increased superoxide dismutase, which is encoded in chromosome 21 and protects against free radical-mediated degradation of hyaluronic acid. Likewise, the genes for two of the three polypeptide chains (a1, a2, and a3) of collagen type IV are found on chromosome 21 (COL6A1 and COL6A2), and it is known that the dermis of fetuses with trisomy 21 is rich in this collagen. ${ }^{10}$

As a probable consequence of hypoplasia or delayed ossification of the nasal bone (Fig. 9) in fetuses with

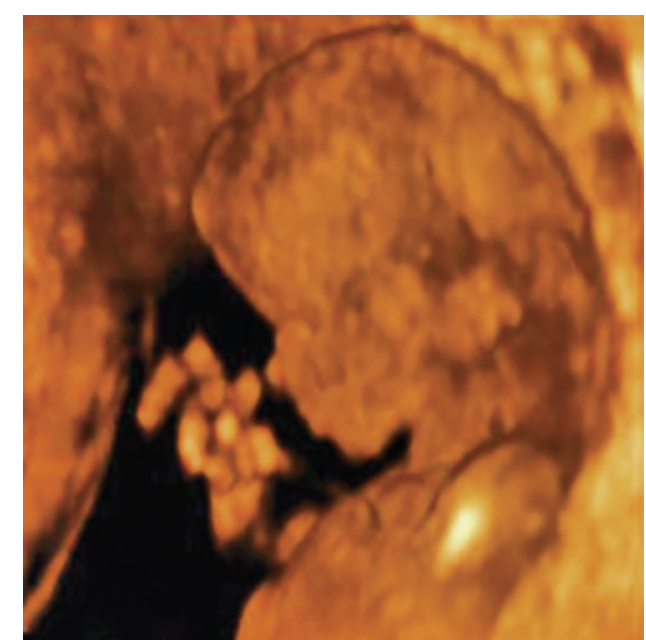

Fig. 8: The 3D fetal profile (the end of 12 weeks) 


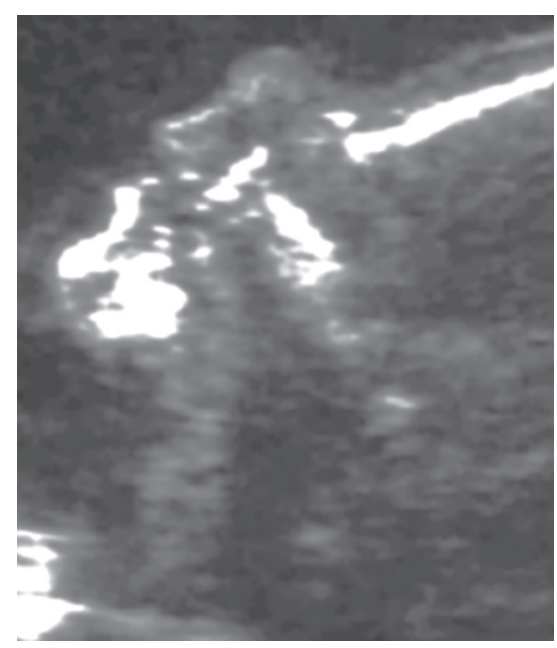

Fig. 9: Delayed nasal bone at trisomy 21 fetus

trisomy 21 , the nasal bone is not visible in 60 to $73 \%$ of first-trimester trisomy 21 fetuses. ${ }^{30,34}$ However, the prevalence of the absent nasal bone among healthy firsttrimester fetuses is low $(0.3-0.6 \%){ }^{30,34,41}$

\section{MEGACYSTIS}

During the first trimester of pregnancy, measuring of fetal bladder is the simplest method for screening the fetal urinary system (Fig. 10). The fetal bladder can be visualized at a CRL of $67 \mathrm{~mm},{ }^{42}$ as a spherical hypoechogenic mass within the fetal pelvis. ${ }^{43}$ Megacystis at the first-trimester fetuses is defined as enlargement of the fetal bladder (longitudinal diameter of the fetal bladder is $>6 \mathrm{~mm}$ ) (Fig. 11). The megacystis can be arranged as being either mild-to-moderate $(8-12 \mathrm{~mm})$ or severe (>17 mm). ${ }^{41,42}$ The fetal bladder diameter/CRL ratio can be an important sample at the assessment, normal range of bladder diameter/CRL is less than $10 \%{ }^{44}$ The association with chromosomal abnormalities has been reported. ${ }^{45}$ There is a correlation between the extent of megacystis and risk of chromosomal defects: In the moderate fetal

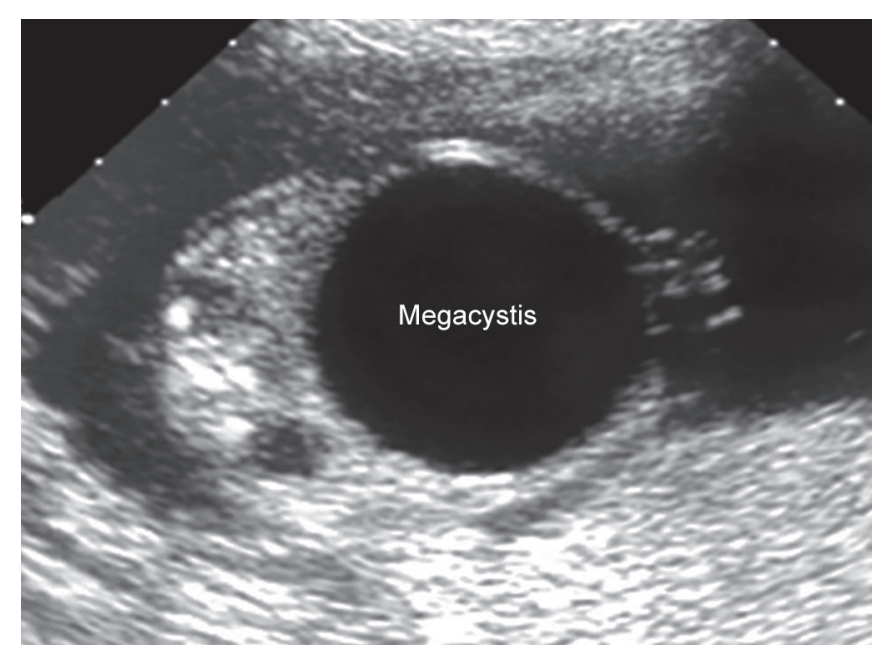

Fig. 11: Severe megacystis at the end of first trimester

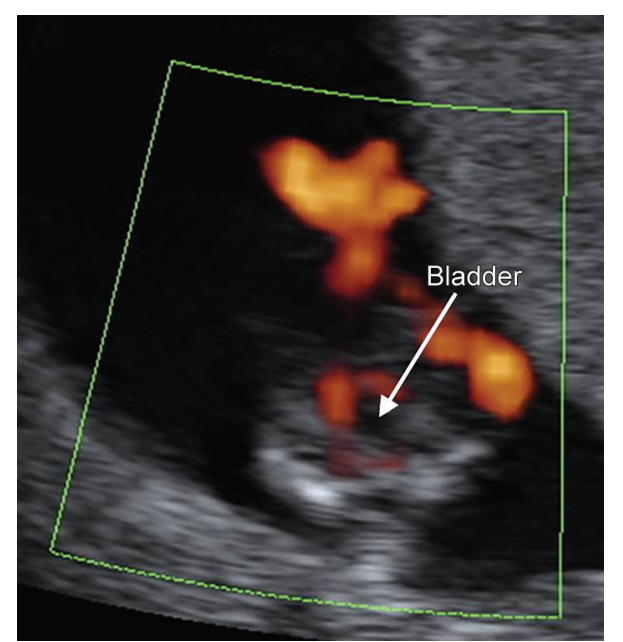

Fig. 10: Measurement of the fetal bladder in a 12-week fetus

megacystis, the risk of chromosomal aberration is about $25 \%$, in the severe fetal megacystis, this risk is about $10 \%$ at 10 to 14 weeks of gestation. ${ }^{46}$

\section{DUCTUS VENOSUS VELOCIMETRY}

The ductus venosus is a primary important vascular structure during the intrauterine life. The importance of this structure is carrying well-oxygenated blood from the placenta and umbilical vein directly to the cerebral and coronary circulation (through the foramen ovale to the left atrium). It behaves as an "arterialized" vessel with a high pulsatile flow and forward velocities throughout the cardiac cycle.

The ductus venosus blood flow can be detected as early as 8 weeks of gestation. ${ }^{45}$ For the ductus venosus velocimetry, the obtained plane is a midsagittal section of the fetal trunk (a narrow, trumpet-like structure). The Doppler sample gate must be placed at the initial portion of the ductus venosus where it originates from the umbilical vein (interrogation angle is $<60^{\circ}$ ). Blood flow in the ductus is characterized by high velocity during ventricular systole (s-wave) and diastole (d-wave) and a presence of forward flow during atrial contraction (a-wave) (Fig. 12A). ${ }^{47}$ The measurement of ductus venosus pulsatility index of the veins (DVPIV) happened on three to five consecutive high-quality ductus venosus waveforms.

Overlap signals originating from different adjacent vessels can cause difficulties in distinction between normal and abnormal waveforms. Ductus venosus flow velocity is approximately three times higher than the flow velocity in the umbilical vein or inferior vena cava. ${ }^{48}$

The absent or reversed flow during the a-wave or a DVPIV of more than 95 percentile (Fig. 12B) can be sign of chromosomal aberration; it has been seen in about 70 to $90 \%$ of fetuses with a chromosomal abnormality. Among fetuses with trisomy 13, ductus venosus studies were found to be more frequently normal. ${ }^{49}$ 

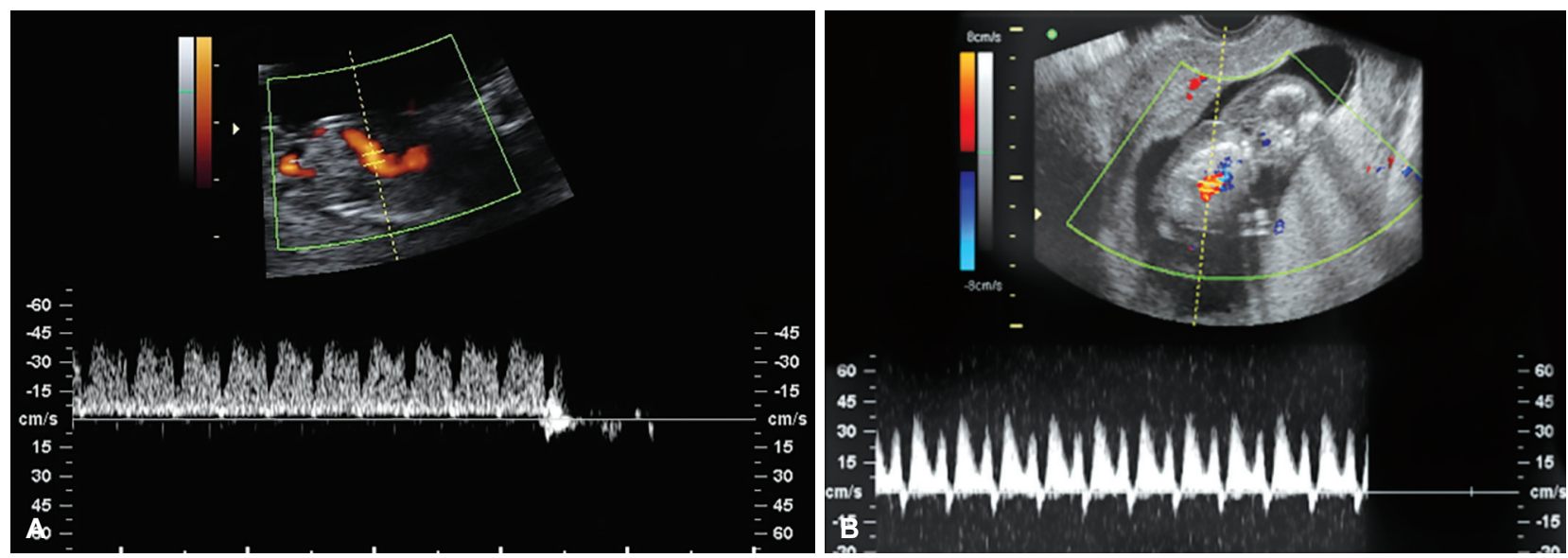

Figs 12A and B: (A) Normal ductus venosus waveform; and (B) The reversed flow during the a-wave (fetus with cystic hygroma)

\section{PULSATILITY INDEX OF THE UMBILICAL ARTERY}

Some studies with umbilical artery pulsatility index (UAPI) have shown that in first-trimester fetuses with trisomy 21, a significantly higher UAPI value is seen than in healthy fetuses. ${ }^{50,51}$ Intriguing is that other studies of the subject did not find significant difference at the UAPI between fetuses with trisomy 21 and normal fetuses. ${ }^{52,53}$ The question is still open and further large prospective studies are needed to explain these differences.

\section{FETAL HEART RATE}

Fetal heart rate (FHR) is detectable at the 6th week of gestation by transvaginal sonography. In this gestational time, the mean heart rate is about 100 beats per minute (bpm). In normal pregnancy, the FHR increases from about $110 \mathrm{bpm}$ at 5 gestational weeks to about 160 to $170 \mathrm{bpm}$ at 9 weeks and then slightly decreases. ${ }^{53}$ The early increase in FHR coincides with the morphological development of the fetal heart, and the subsequent FHR decrease might be the result of functional maturation of the fetal parasympathetic system. ${ }^{54,55}$ The FHR abnormalities can be found among aneuploid fetuses. In trisomies 21 and 13, monosomy X, the significant mean increase in the fetal heart frequency has been described ${ }^{56}$ Then again, in fetuses with trisomy 18 or triploidy, the mean FHR is significantly reduced.

\section{UMBILICAL CORD}

Diameter of umbilical cord can be measured during the first trimester (10-14 weeks scan). There is the observation that fetuses with chromosomal defects, compared with healthy fetuses, have an increased diameter of the umbilical cord (above the 95th centile of reference value). ${ }^{57}$ Normally, there are two umbilical arteries around the fetal bladder, which can be visualized during the firsttrimester scan (Fig. 13). The presence of two-vessel cord

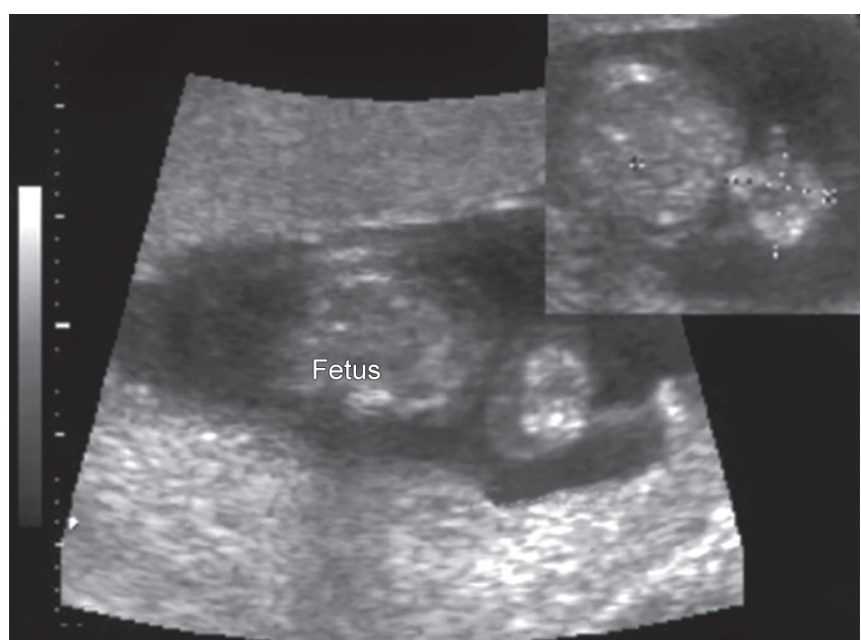

Fig. 13: A $12 \times 10 \mathrm{~mm}$ size omphalocele in a 13-week fetus

(one vena and one artery) can also be a marker for fetal aneuploidy (singular umbilical artery).

About $1 \%$ of pregnancies present with a two-vessel cord, among these, about 1 to $10 \%$ have an aneuploidy.

\section{OMPHALOCELE}

The return of intestine into the peritoneal cavity normally takes place around the 12th week of gestation. Omphalocele (exomphalos) (Fig. 14) is a ventral wall defect characterized by the herniation of intra-abdominal organs (bowel loops, stomach, and liver) into the base of umbilical cord, with a covering amnioperitoneal membrane. The omphalocele can be diagnosed during the first-trimester scan (above 12th week of gestation). Association with chromosomal aberrations is 35 to $58 \%$. The 3D first-trimester ultrasonography can be helpful in identification of the omphalocele.

\section{OTHER ABNORMALITIES}

Fetal kidney and bladder can be clearly seen in the 12th week of gestation. The size of normal fetal kidney 


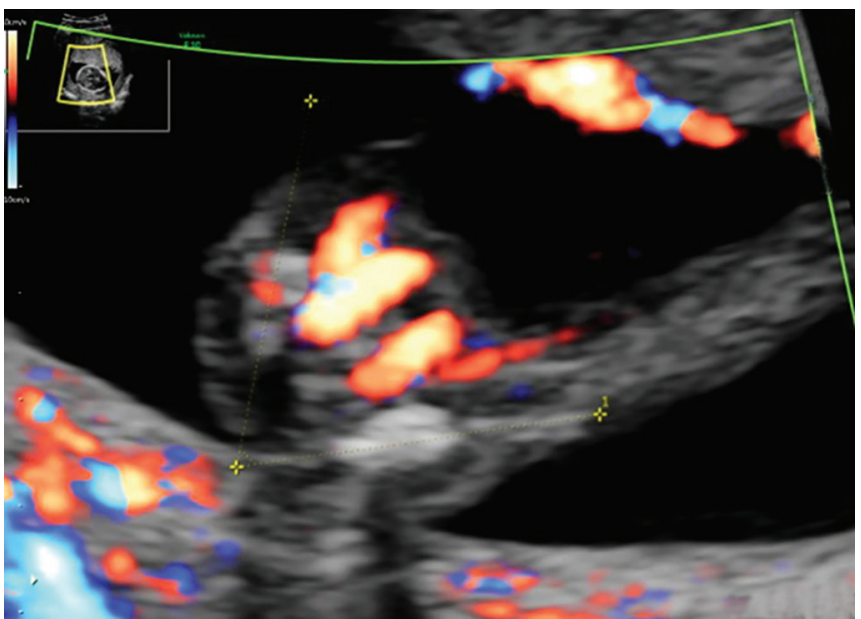

Fig. 14: Two umbilical arteries around the fetal bladder (transverse section of the fetal pelvic)

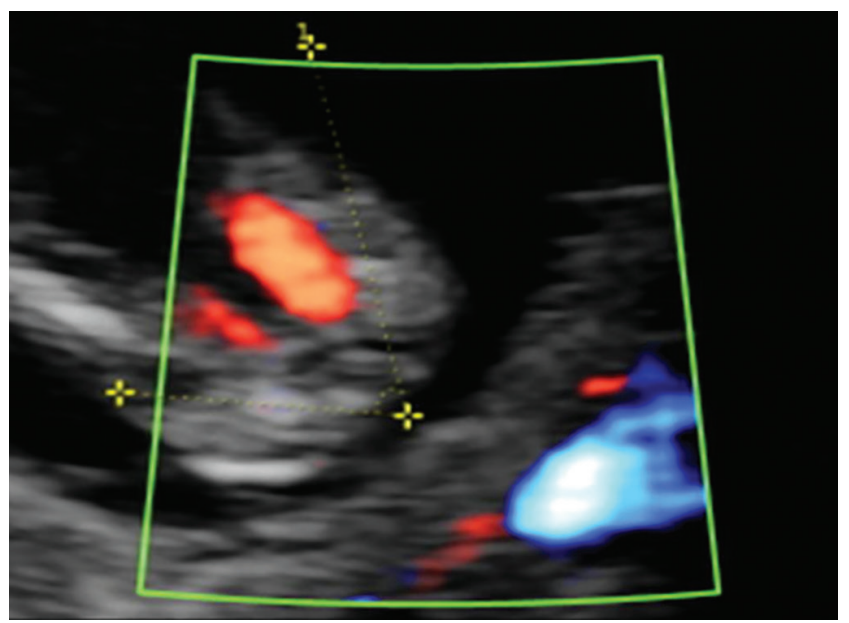

Fig. 15: Fetal iliac angle measurement on the transverse section of the fetal pelvis (12-week fetus) pelvis at the end of the first trimester has not yet been established..$^{58}$ The fetal pyelectasis is unilateral or bilateral dilatation of the renal pelvis. The proposed $3 \mathrm{~mm}$, as a higher level for normal renal pelvis anteroposterior diameter, ${ }^{59}$ can be used for the border of pyelectasis at the end of first trimester.

Presence of the bilateral pyelectasis increases the risk of aneuploidy by about 1.5 to 2 times. The incidence of pyelectasis among fetuses with trisomy 21 is about 17 to $25 \%$, compared with only 2.1 to $2.8 \%$ in healthy fetuses. ${ }^{60,61}$

Choroid plexus cysts (CPCs) are relatively common in the first trimester. ${ }^{62}$ The choroid plexus can be visualized as early as 8 weeks of gestation. ${ }^{63}$ The size, form, position of choroid plexus do change during the early stage of pregnancy. ${ }^{63}$ In the first trimester, the size of the majority of CPCs is 1 to $2 \mathrm{~mm}^{.63}$

The CPCs are significantly associated with trisomy 18 at midgestation. ${ }^{64}$ The association of CPCs with other chromosomal abnormalities is controversial. ${ }^{62,65,66}$

Fetal structural malformations are evident in the second and third trimesters. First-trimester studies of fetal anatomy are limited (for the technical reasons and due to the natural development of the organs). Certain structural malformations in the first trimester have recently been described in association with chromosomal abnormalities (holoprosencephaly, ventriculomegaly, facial cleft, micrognathia), etc.

\section{FUTURE POSSIBILITIES}

With the evolution of ultrasound technique, the advancement of sonographic markers for fetal aneuploidy is expected.

Experiences with the fetal iliac angle measurement at the second trimester ${ }^{67-71}$ can be useful at the first-trimester scan, but this statement is unproven yet. The fetal iliac bones can be visualized during the first-trimester scan; the angle between them can be measured (Fig. 15). In the future, large prospective studies are needed to investigate the usefulness of this marker.

\section{REFERENCES}

1. Hernádi L, Töröcsik M. Screening for fetal anomalies in the 12th week of pregnancy by transvaginal sonography in an unselected population. Prenat Diagn 1997 Aug;17(8): 753-759.

2. Benacerraf BR, Barss VA, Laboda LA. A sonographic sign for the detection in the second trimester of the fetuses with Down's syndrome. Am J Obstet Gynecol 1985 Apr;151(8):1078-1079.

3. Nicolaides KH, Azar G, Byrne D, Mansur C, Marks K. Fetal nuchal translucency screening for chromosomal defects in first trimester of pregnancy. BMJ 1992 Apr;304(6831):867-869.

4. Malone FD, D'Alton ME; Society of Maternal-Fetal Medicine. First-trimester sonographic screening for Down syndrome. Obstet Gynecol 2003 Nov;102(5 Pt 1):1066-1079.

5. Moscoso G. Fetal nuchal translucency: a need to understand the physiological basis. Ultrasound Obstet Gynecol 1995 Jan;5(1):6-8.

6. von Kaisenberg CS, Brand-Saberi B, Jonat W, Nicolaides KH. Pathophysiology of increased nuchal translucency in chromosomally abnormal fetuses. Prenat Neonat Med 1999;4:431-440.

7. Souka AP, Krampl E, Bakalis S, Heath V, Nicolaides KH. Outcome of pregnancy in chromosomally normal fetuses with increased nuchal translucency in the first trimester. Ultrasound Obstet Gynecol 2001 Jul;18(1):9-17.

8. Hyett J, Moscoso G, Nicolaides K. Abnormalities of the heart and great arteries in first trimester chromosomally abnormal fetuses. Am J Med Genet 1997 Mar;69(2):207-216.

9. Monni G, Zoppi MA. New ultrasonographic markers of aneuploidies: nasal bones. Ultrasound Rev Obstet Gynecol 2002;2:229-234.

10. von Kaisenberg CS, Brand-Saberi B, Christ B, Vallian S, Farzaneh F, Nicolaides KH. Collagen type IV gene expression in the skin of trisomy 21 fetuses. Obstet Gynecol 1998 Mar;91(3):319-323.

11. von Kaisenberg CS, Krenn V, Ludwig M, Nicolaides $\mathrm{KH}$, Brand-Saberi B. Morphological classification of nuchal skin in human fetuses with trisomy 21, 18 and 13 at 12-18 weeks and in a trisomy 16 mouse. Anat Embryol (Berl) 1998 Feb;197(2):105-124. 
12. Snijders RJ, Noble P, Sebire N, Souka A, Nicolaides KH. UK multicentre project on assessment of risk of trisomy 21 by maternal age and fetal nuchal-translucency thickness at 10-14 weeks of gestation. Lancet 1998 Aug;352(9125):343-346.

13. Nicolaides KH, Snijders RJ, Cuckle HS. Correct estimation of parameters for ultrasound nuchal translucency screening. Prenat Diagn 1998 May;18(5):519-523.

14. Krantz DA, Hallahan TW, Orlandi F, Buchanan P, Larsen JW Jr, Macri JN. First-trimester Down syndrome screening using dried blood biochemistry and nuchal translucency. Obstet Gynecol 2000 Aug;96(2):207-213.

15. Spencer K, Spencer CE, Power M, Moakes A, Nicolaides KH. One stop clinic for assessment of risk for fetal anomalies: a report of the first year of prospective screening for chromosomal anomalies in the first trimester. BJOG 2000 Oct;107(10):1271-1275.

16. Spencer K, Souter V, Tul N, Snijders R, Nicolaides KH. A screening program for trisomy 21 at 10-14 weeks using fetal nuchal translucency, maternal serum free beta-human chorionic gonadotropin and pregnancy-associated plasma protein-A. Ultrasound Obstet Gynecol 1999 Apr;13(4):231-237.

17. Evans MI, Van Decruyes H, Nicolaides KH. Nuchal translucency measurements for first-trimester screening: the "price" of inaccuracy. Fetal Diagn Ther 2007 Jul;22(6):401-404.

18. Zoppi MA, Ibba RM, Putzolu M, Floris M, Monni G. Assessment of risk for chromosomal abnormalities at 10-14 weeks of gestation by nuchal translucency and maternal age in 5210 fetuses carried out at a single center. Fetal Diagn Ther 2000 May-June;15(3):170-173.

19. Descamps P, Jourdain O, Paillet C, Toutain A, Guichet A, Pourcelot D, Gold F, Castiel M, Body G. Etiology, prognosis and management of nuchal cystic hygroma: 25 new cases and literature review. Eur J Obstet Gynecol Reprod Biol 1997 Jan;71(1):3-10.

20. Abramowicz JS, Warsof SL, Doyle DL, Smith D, Levy DL. Congenital cystic hygroma of the neck diagnosed prenatally: outcome with normal and abnormal karyotype. Prenat Diagn 1989 May;9(5):321-327.

21. Johnson MP, Johnson A, Holzgreve W, Isada NB, Wapner RJ, Treadwell MC, Heeger S, Evans MI. First-trimester simple hygroma: cause and outcome. Am J Obstet Gynecol1993 Jan;168(1 Pt 1):156-161.

22. Newman DE, Cooperberg PL. Genetics of sonographically detected intrauterine fetal cystic hygromas. J Can Assoc Radiol 1984 Mar;35(1):77-79.

23. Pearce JM, Griffin D, Campbell S. Cystic hygromata in trisomy 18 and 21. Prenat Diagn 1984 Sep-Oct;4(5):371-375.

24. Reuss A, Pijpers L, Schampers PT, Wladimiroff JW, Sachs ES. The importance of chorionic villus sampling after first trimester diagnosis of cystic hygroma. Prenat Diagn 1987 May;7(4):299-301.

25. Rosati P, Guariglia L. Transvaginal ultrasound detection of septated and non-septated cystic hygroma in early pregnancy. Fetal Diagn Ther 1997 May-Jun;12(3):132-135.

26. Drugan A, Johnson MP, Evans MI. Ultrasound screening for fetal chromosome anomalies. Am J Med Genet 2000 Jan;90(2):98-107.

27. Schemmer G, Wapner RJ, Johnson A, Schemmer M, Norton HJ, Anderson WE. First trimester growth patterns of aneuploid fetuses. Prenat Diagn1997 Feb;17(2):155-159.

28. Sherrod C, Sebire NJ, Soares W, Snijders RJ, Nicolaides KH. Prenatal diagnosis of trisomy 18 at the 10-14 week ultrasound scan. Ultrasound Obstet Gynecol 1997 Dec;10(6):387-390.
29. Kjaer I, Keeling JW, Hansen BF. Pattern of malformations in the axial skeleton in human trisomy 18 fetuses. Am J Med Genet 1996 Nov;65(4):332-336.

30. Cicero S, Curcio P, Papageorghiou A, Sonek J, Nicolaides K. Absence of nasal bone in fetuses with trisomy 21 at 11-14 weeks of gestation: an observational study. Lancet 2001 Nov;358(9294):1665-1667.

31. Moss, ML. The functional matrix. In: Kraus BS, Riedel TA, editors. Vistas in Orthodontics. Philadelphia: Lea and Febiger; 1962.

32. Prefumo F, Sairam S, Bhide A, Penna L, Hollis B, Thilaganathan B. Maternal ethnic origin and fetal nasal bones at 11-14 weeks of gestation. BJOG 2004 Feb;111(2):109-112.

33. Sonek JD, Nicolaides KH. Prenatal ultrasonographic diagnosis of nasal bone abnormalities in three fetuses with Down syndrome. Am J Obstet Gynecol 2002 Jan;186(1):139-141.

34. Otaño L, Aiello H, Igarzábal L, Matayoshi T, Gadow EC. Association between first trimester absence of fetal nasal bone on ultrasound and Down syndrome. Prenat Diagn 2002 Oct;22(10):930-932.

35. Palermo FG, Albuquerque Dde P, Martins WP, AraujoJúnior E, Bruns RF. Auditing fetal nasal bone images in the first trimester of pregnancy: results from a peer review program. J Matern Fetal Neonatal Med 2016 Sep;29(17):2874-2877.

36. Keeling JW, Hansen BF, Kjaer I. Pattern of malformation in the axial skeleton in human trisomy 21 fetuses. Am J Med Genet 1997 Feb;68(4):466-471.

37. Kjaer I, Keeling JW, Reinthoft I, Nolting D, Hansen BF. Pituitary gland and sellaturcica in human trisomy 21 fetuses related to axial skeletal development. Am J Med Genet 1998 Dec;80(5):494-500.

38. Ibba RM, Zoppi MA, Floris M, Putzolu M, Monni G, Todde PF, Sardu G. Otocephaly: prenatal diagnosis of a new case and etiopathogenetic considerations. Am J Med Genet 2000 Feb;90(5):427-429.

39. Mooney, MP.; Siegel, MI. Understanding craniofacial anomalies. New York, NY: Wiley-Liss; 2002. p. 50-54.

40. Böhlandt S, von Kaisenberg CS, Wewetzer K, Christ B, Nicolaides KH, Brand-Saberi B. Hyaluronan in the nuchal skin of chromosomally abnormal fetuses. Hum Reprod 2000 May;15(5):1155-1158.

41. Monni G, Zoppi MA, Ibba RM. Absence of nasal bone and detection of trisomy 21. Lancet 2002 Apr;359(9314):1343.

42. Maymon R, Schneider D, Reish O, Herman A. First trimester spontaneous resolution of megacystis in Down syndrome fetus. Prenat Diagn 2001 Sep;21(9):790-791.

43. Braithwaite JM, Armstrong MA, Economides DL. Assessment of fetal anatomy at 12 to 13 weeks of gestation by transabdominal and transvaginal sonography. Br J Obstet Gynaecol 1996 Jan;103(1):82-85.

44. Sebire NJ, von Kaisenberg C, Rubio C, Snijders RJ, Nicolaides KH. Fetal megacystis at 10-14 weeks of gestation. Ultrasound Obstet Gynecol 1996 Dec;8(6):387-390.

45. Favre R, Kohler M, Gasser B, Muller F, Nisand I. Early fetal megacystis between 11 and 15 weeks of gestation. Ultrasound Obstet Gynecol 1999 Dec;14(6):402-406.

46. Liao AW, Sebire NJ, Geerts L, Cicero S, Nicolaides KH. Megacystis at 10-14 weeks of gestation: chromosomal defects outcome according to bladder length. Ultrasound Obstet Gynecol 2003 Apr;21(4):338-341.

47. Huisman TW, Stewart PA, Wladimiroff JW. Doppler assessment of the normal early fetal circulation. Ultrasound Obstet Gynecol 1992 Jul;2(4):300-305. 
48. Sherer DM, Fromberg RA, Divon MY. Prenatal ultrasonographic assessment of the ductus venosus: a review. Obstet Gynecol 1996 Oct;88(4 Pt 1):626-632.

49. Bilardo CM, Müller MA, Zikuling L, Schipper M, Hecher K. Ductus venosus studies in fetuses at high risk for chromosomal or heart abnormalities: relationship with nuchal translucency measurement and fetal outcome. Ultrasound Obstet Gynecol 2001 Apr;17(4):288-294.

50. Martinez Crespo JM, Comas C, Ojuel H, Puerto B, Borrell A, Fortuny A. Umbilical artery pulsatility index in early pregnancies with chromosome anomalies. Br J Obstet Gynaecol 1996 Apr;103(4):330-334.

51. Zoppi MA, Ibba RM, Putzolu M, Floris M, Monni G. First trimester umbilical artery pulsatility index in fetuses presenting enlarged nuchal translucency. Prenat Diagn 2000 Sep;20(9):701-704.

52. Brown R, Di-Luzio L, Gomes C, Nicolaides KH. The umbilical artery pulsatility index in the first trimester: is there an association with increased nuchal translucency or chromosomal abnormality? Ultrasound Obstet Gynecol 1998 Oct;12(4):244-247.

53. Jauniaux E, Gavrill P, Khun P, Kurdi W, Hyett J, Nicolaides KH. Fetal heart rate and umbilico-placental Doppler flow velocity waveforms in early pregnancies with a chromosomal abnormality and/or an increased nuchal translucency thickness. Hum Reprod 1996 Feb;11(2):435-439.

54. Wisser J, Dirschedl P. Embryonic heart rate in dated human embryos. Early Hum Dev 1994 May;37(2):107-115.

55. Wladimiroff JW, Seelen JC. Fetal heart action in early pregnancy. Development of fetal vagal function. Eur J Obstet Gynecol 1972 Dec;2(2):55-63.

56. Hyett JA, Noble PL, Snijders RJ, Montenegro N, Nicolaides $\mathrm{KH}$. Fetal heart rate in trisomy 21 and other chromosomal abnormalities at 10-14 weeks of gestation. Ultrasound Obstet Gynecol 1996 Apr;7(4):239-244.

57. Ghezzi F, Raio L, Di Naro E, Franchi M, Buttarelli M, Schneider H. First-trimester umbilical cord diameter: a novel marker of fetal aneuploidy. Ultrasound Obstet Gynecol 2002 Mar;19(3):235-239.

58. Rosati P, Guariglia P. Transvaginal sonographic assessment of the fetal urinary tract in early pregnancy. Ultrasound Obstet Gynecol 1996 Feb;7(2):95-100.

59. Bronshtein M, Yoffe N, Brandes JM, Blumenfeld Z. First and early second-trimester diagnosis of fetal urinary tract anomalies using transvaginal sonography. Prenat Diagn 1990 Oct;10(10):653-666.

60. Benacerraf BR, Mandell J, Estroff JA, Harlow BL, Frigoletto FD. Fetal pyelectasis: a possible association with Down syndrome. Obstet Gynecol 1990 Jul;76(1):58-60.

61. Corteville JE, Dicke JM, Crane JP. Fetal pyelectasis and Down syndrome: is genetic amniocentesis warranted? Obstet Gynecol 1992 May;79(5 Pt 1):770-772.

62. Whitlow BJ, Lazanakis ML, Kadir RA, Chatzipapas I, Economides DL. The significance of choroid plexus cysts, echogenic heart fociand renal pyelectasis in the first trimester. Ultrasound Obstet Gynecol 1998 Dec;12(6):385-390.

63. Blaas HG, Eik-Nes SH, Kiserud T, Hellevik LR. Early development of the hindbrain: a longitudinal ultrasound study from 7 to 12 weeks of gestation. Ultrasound Obstet Gynecol 1995 Mar;5(3):151-160.

64. Snijders RJ, Shawa L, Nicolaides KH. Fetal chorioid plexuscysts and trisomy 18: assessment of risk based on ultrasound findings and maternal age. Prenat Diagn 1994 Dec;14(12):1119-1127.

65. Gupta JK, Cave M, Lilford RJ, Farrell TA, Irving HC, Mason G, Hau CM. Clinical significanceof fetal choroids plexus cysts. Lancet 1995 Sep;346(8977):724-728.

66. Bromley B, Lieberman E, Benacerraf BR. Choroid plexuscysts: not associated with Down syndrome. Ultrasound Obstet Gynecol 1996 Oct;8(4):232-235.

67. Shipp TD, Bromley B, Lieberman E, Benacerraf BR. The iliac angle as a sonographic marker for Down syndrome in second-trimester fetuses. Obstet Gynecol 1997 Mar;89(3): 446-450.

68. Belics Z, Beke A, Csabay L, Szabó I, Papp Z. Sonographic measurement of the fetal iliac angle in trisomy 21,18 and 13 . Fetal Diagn Ther 2003 Jan-Feb;18(1):47-50.

69. Bork MD, Egan JF, Cusick W, Borgida AF, Campbell WA, Rodis JF. Iliac wing angle as a marker for trisomy 21 in the second trimester. Obstet Gynecol 1997 May;89(5 Pt 1):734-737.

70. Grangé G, Thoury A, Dupont J, Pannier E, LeRhun F, Goussot Souchet M, Goffinet F, Cabrol D. Sonographic measurement of the fetal iliac angle cannot be used alone as a marker for trisomy 21. Fetal Diagn Ther 2000 Jan-Feb;15(1):41-45.

71. Belics Z, Fekete T, Beke A, Szabó I. Prenatal ultrasonographic measurement of the fetal iliac angle during the first and second trimester of pregnancy. Prenat Diagn 2011 Apr;31(4): 351-355. 